\title{
The Roles of the Long Non-Coding RNA Transcripts in Cardiovascular Diseases
}

\author{
Burcu BAYOĞLU, Müjgan CENGİZ \\ Division of Medical Biology, İstanbul University Cerrahpaşa School of Medicine, İstanbul, Turkey
}

\section{ABSTRACT}

For many years, proteins have been known be the major regulators in biological processes such as transcription and translation. However, in recent years, with the advent of high-throughput sequencing technology, a high-resolution map of the human transcriptome was made and a large number of non-protein coding RNA genes were discovered. Non-protein coding RNA genes (ncRNAs) are classified according to their size. Long non-coding RNAs (lncRNAs) are a group of ncRNAs that are $>200$ nucleotides long. LncRNAs are involved in many biological processes. Expression levels of and genetic variations in lncRNAs contribute to in vivo and in vitro pathophysiological processes and have been associated with many diseases. In recent years, numerous lncRNAs, which are associated with cardiovascular disease (CVD), have been identified. One of the major causes of CVD is atherosclerosis. The molecular processes involved in the formation and progression of atherosclerosis in vascular smooth muscle cells, endothelial cells, and monocytes/macrophages play an important role in the development of CVD. In the future, a better understanding of the biological functions of lncRNAs with their ever-increasing importance in the formation and development of atherosclerosis will shed light on the development of novel therapeutic approaches for CVD.

Keywords: Long non-coding RNA, cardiovascular disease, atherosclerosis, endothelial cells, vascular smooth muscle cells

\section{Introduction}

Cardiovascular diseases (CVD) are among the most important causes of mortality in the world. Although the causes of CVD are variable, atherosclerosis is seen as the most common cause (1). Coding transcripts constitute $<3 \%$ of the genome. The non-coding transcripts that constitute $>80 \%$ of the genome were previously defined as "junk transcripts" or "transcriptional noise" (2). Long non-coding RNAs (lncRNAs) constitute a new class of RNAs, larger than 200 nucleotides, do not code proteins. Studies have shown that lncRNAs have critical roles in cellular processes, such as the development and differentiation in the control of gene expression. The lncRNAs regulate gene expression in the stages of epigenetic control, transcription, RNA processing, and translation. The first identified lncRNA is X inactive specific transcript (XIST) (3). Subsequent studies have identified several lncRNAs that play a vital role in cancer progression and metastasis, cell proliferation, and apoptosis $(4,5)$. Investigating the role of lncRNAs in CVD will contribute to the understanding of the molecular mechanism of atherosclerosis and to the development of new therapeutic approaches in CVD.

\section{Clinical and Research Effects}

\section{General characteristics of long non-coding RNAs}

A large part of the mammalian genome is transcribed as non-coding RNA (ncRNA). The lncRNAs, which have limited coding potential, constitute a large class as RNA transcripts larger than 200 nucleotides. The lncRNAs function as critical epigenetic regulators of gene expression. The common features of protein-coding RNAs include RNA polymerase II processing and 5' cap and 3' polyadenylation. However, lncRNAs do not contain open reading frames 
and are generally expressed much lesser levels compared mRNAs. The lncRNAs are alternatively spliced. Unlike mRNA and miRNAs, IncRNAs have not been considerably conserved among species (6).

A large number of lncRNAs have been identified with the high throughput DNA sequencing technologies in recent years. Although the role of lncRNAs is not considerably known yet, it is thought that they regulate the expressions of target genes and have important roles in many biological processes. They exhibit biological functions as important regulators of gene transcription particularly in various types of cancer and vascular diseases (7). The numbers of IncRNA genes and transcripts have most commonly been defined in humans and mice. In the NONCODE database (http: // www.noncode.org), 141353 lncRNA transcripts and 90062 lncRNA genes have been identified to date. This number appears to be 117405 lncRNA transcripts and $79940 \mathrm{ln}$ cRNA genes in mouse. The biological functions have been characterized for a very few of a total of $324646 \operatorname{lncRNA}$ genes identified to date. The lncRNAs may be intergenic, intronic, bidirectional, enhancer, and sense- or antisenseoriented, depending on their genomic location. Intergenic lncRNAs (lincRNAs) are transcribed between two proteincoding genes, and intronic lncRNAs are transcribed in the introns of protein-coding genes. The bidirectional promoter lncRNAs are transcribed at a distance of about $1 \mathrm{~kb}$ to the promoter from the opposite direction of the protein-coding transcript. Enhancer lncRNAs (elncRNAs) are usually smaller than $2 \mathrm{~kb}$ and are transcribed in the enhancer regions of the genome. Sense lncRNAs are transcribed from the sense strand of protein-coding genes and can contain introns and exons. Antisense-oriented lncRNAs are transcribed from the antisense strand of protein-coding genes and can overlap with exons, introns, or both belonging to the protein-coding gene in the sense strand. Although the functions of lncRNAs have not yet been elucidated in detail, they are known to participate in cellular functions through epigenetic, transcriptional, and post-transcriptional regulations. LncRNAs are mostly found in the nucleus and regulate gene expression at the epigenetic level. LncRNAs contribute to gene expression regulation by serving as signal, decoy, guide, or scaffold. Some lncRNAs have undertaken more than one of these tasks.

\section{Epigenetic regulation of lncRNAs}

Epigenetics indicate hereditary changes in the gene phenotype without any change in the DNA sequence. These hereditary changes mostly correspond to the changes in histone post-translational modifications and chromatin structure. Epigenetic modifications include DNA methylation, histone modifications, and ncRNAs. DNA methylation usually occurs in $\mathrm{CpG}$ regions (8). DNA methylation plays an important role in the control of gene expression during $\mathrm{X}$ chromosome inactivation, genomic imprinting and development, and differentiation. Studies have shown that IncRNAs cause histone modification by combining with chromatin-remodeling complexes and thus activate or inhibit transcription. The lncRNAs can play a role in affecting the genomic imprinting and dosage compensation $(9,10)$. The XIST IncRNA plays an important role in $\mathrm{X}$ chromosome inactivation in female mammals (11). There is a repeating motif called "repeat A" at the 5' end of XIST. Repeat A motif is directly linked to EZH2, which is the subunit of Polycomb repressive complex 2 (PRC2). PRC2 is a protein complex that catalyzes the repressor epigenetic modifications. PRC2 transcriptionally silences the $\mathrm{X}$ chromosome by tri-methylating histone $\mathrm{H} 3$ lysine 27 (H3K27me3) (12). In another study, it was reported that the KCNQ1OT1, which is an IncRNA, was required for the maintenance of the silencing of the imprinted gene UIG. Through the signal lncRNA function, KCNQ1OT1 has been reported to enable the accumulation of various protein complexes to the region and direct the $\mathrm{CpG}$ methylation in differentially methylated regions and conserve the maintenance (13).

\section{Transcriptional and post-transcriptional regulations of LncRNAs}

LncRNAs regulate gene transcription by various mechanisms. These mechanisms are regulating the activities of transcription factors, preventing the expression of neighboring genes, blocking promoter regions, and controlling the interaction with proteins. Enhancer IncRNAs regulate the expressions of target genes by creating chromosomal loops between enhancer and promoter regions of genes. In a study, IncRNA-Evf2 has been reported to suppress Dlx $5 / 6$ gene expression by regulating the methylation of Dlx $5 / 6$ gene, which is specific to the enhancer region (14). In another study, it has been shown that the lncRNA-SRG1 transcript inhibits the binding of activator proteins to the SER3 gene promoter and accordingly regulates the suppression of SER3 (15). Wang et al. (16) reported that ncRNA CCND1 aggregates TLS, which is a RNA binding protein, into the CCND1 promoter region and causes gene-specific suppression of CCND1.

LncRNAs can regulate alternative splicing, degradation, and mRNA stability. The lncRNAs that function as a decoy can suppress gene expression by linking various transcription factors. Lin et al. (17) reported that the disorder in lncRNA $\sum$ RNA, known as MALAT1 in humans, altered splicing activities of the genes coding heterogeneous nuclear ribonucleoproteins (hnRNPs). LncRNA-NEAT1 transcripts have been reported to strain the geometry of paraspeckle proteins (PSPs) and to inhibit the protein translation of mRNA by prolonging the survival of mRNAs in the nucleus (18). LncRNAs can also act as endogenous decoys for miRNAs, 
for example, miR-135 and miR-133 target MEF2C and MAML1, respectively, and regulate myoblast differentiation. Linc-MD1 contains two regions that bind to miRNA and regulate the expression levels of MEF2C and MAML1 by linking miR-135 and miR-133, respectively (19). Guide lncRNAs bind to RNPs, direct their localization to the specific target sites, and can activate or suppress the expression of the target genes.

\section{Importance of lncRNAs in the cells involved in the formation of atherosclerosis}

Vascular smooth muscle cells (VSMCs), endothelial cells (EC), and macrophages are among the cells that play a role in the development of atherosclerosis (20). In recent years, genome-wide association studies have shown that chromosome 9p21 locus (Chr9p21) is a strong risk factor for coronary artery disease (CAD) (21). It has also been shown in studies conducted in Turkish population that various single nucleotide polymorphisms present in this locus form a predisposition to CAD development and that some variants affect the severity of disease (22). This region is adjacent to the INK4 locus and codes an lncRNA that acts as a scaffold and is called as ANRIL (CDKN2B-AS). ANRIL expression has been observed in several cells and tissues isolated from SMCs, ECs, macrophages, carotid, and atherectomy (23). A relationship between the severity of atherosclerosis and ANRIL expression has also been described (24). Yap et al. (25) reported the association between ANRIL knockdown and increase in the expression of the cyclin-dependent kinase inhibitor 2A (CDKN2A) and decrease in H3K27ME3. However, another study showed that CDKN2B expression was elevated due to the inhibition of the binding of SUZ12 to the Chr9p21 region as a result of the knockdown of ANRIL gene with shRNA (26). In the Turkish population, a significant relationship has been detected between the genetic variants found on the IncRNA gene ANRIL and the risk of metabolic syndrome, which is associated with risk factors that play a role in the development of hypertension and CVD $(27,28)$. In addition, the expression levels of ANRIL transcripts in atherosclerotic carotid plaques and saphenous tissues of the patients undergoing carotid endarterectomy in the Turkish society were investigated. There was a positive correlation between the vascular stenosis grade and the CD$\mathrm{KN} 2 \mathrm{~A}$ gene, which is the gene adjacent to the ANRIL gene, and the expression level of the ANRIL transcript was shown for the first time in the saphenous tissues (29). In addition, Holdt et al. (23) reported the importance of Alu motifs in the proatherogenic functions of ANRIL. ANRIL can regulate the target genes through Alu motifs which are located both on itself and on the promoter regions of the target genes. As a result, a decrease is observed in apoptosis along with the increase in cell proliferation and cell adhesion, which play a critical role in the formation of atherosclerosis.
The function of ANRIL has still not been fully understood. This is because the differential transcript variants of ANRIL have different regulatory and biological properties. This makes the ANRIL mechanism complex (2). Jarinova et al. (30) reported that the DQ485454 and EU741058 levels, which are among the short ANRIL variants increased and the long variant DQ 485453 level decreased in those having risk alleles in whole blood. Another study found that the levels of transcript EU741058 increased but the DQ485454 transcript variant did not change in those carrying the risk haplotype in peripheral blood mononuclear cells and atherosclerotic plaques. In addition, the correlation of EU741058 and NR_003529 transcripts with the severity of atherosclerosis has been reported (31). In the Turkish society, Bayoğlu et al. (29) reported that ANRIL NR_003529 transcript levels increased in atherosclerotic carotid plaques in comparison to saphenous tissue, but this result did not reach the level of statistical significance.

Pathological angiogenesis resulting from cell proliferation, cell motility and immune or inflammatory response play a critical role in the development of atherosclerosis (32).In a study, it was reported that lncRNA-MIAT (retinal non-coding RNA 2 or Gomafu) was induced by high glucose levels. Endothelial cell proliferation, migration, and tube formation were inhibited along with the knockdown of the MIAT gene, and it was demonstrated that the retinal microvascular dysfunction in diabetic rats improved (32). The knockdown of the MIAT gene has been shown to increase the expressions of vascular endothelial growth factor (VEGF), tumor necrosis factor (TNF)- $\alpha$ and intracellular adhesion molecule-1 (ICAM-1). In addition, it has been shown that miR-150-5p directly targets and suppresses VEGF expression due to the miR-150-5p regions that VEGF contained $(32,33)$.

It has been shown that lncRNA as metastasis-associated lung adenocarcinoma transcript (MALAT1) regulates genes in EC and induces proliferation (34). It has been reported that silencing of MALAT1 induces the transition phenotype of the EC from the proliferation state to the migration state (35). Such phenotypic changes increase cell migration in vascular and inhibit the cell cycle progression in vitro and in vivo. With the silencing of MALAT1, the level of CCNA2, CCNB1, and CCNB2, which are the cell cycle regulator genes, decreased; however, the levels of cell cycle inhibitor genes p21 and p27Kip1 increased. It has been shown in a study that MALAT1 is expressed in both EC and muscle cells and promotes the differentiation of the skeletal muscle (36).

In addition to the changes in ECs, the proliferation and migration of VSMC constitute an important step in the formation and development of atherosclerosis. P53, which 
is an important molecule in cell cycle and apoptosis control, has also shown to be involved in the formation of atherosclerosis (37). It has been reported in a study that p53 is inactivated in the development of atherosclerosis (38). Huarte et al. (39) reported that lincRNA-p21, which is a p53-induced lncRNA, reduced the expressions of various $\mathrm{p} 53$ target genes by interacting with the $\mathrm{p} 53$ repressor complex. In another study, it has been demonstrated that lincRNA-p21 suppresses cell proliferation, induces apoptosis, and leads to neointimal hyperplasia along with the knockdown of lincRNA-p21. LincRNA-p21 increases the p53 activity by directly binding to mouse double minute 2 (MDM2); therefore, MDM2-mediated inhibition of p53 decreases and the binding of p53 to p300 is facilitated (40). In another study investigating the role of lncRNAs in smooth muscle cells, angiotensin II has been shown to induce VSMC hyperproliferation and hypertrophy (41). The knockdown of lnc-Ang362 in angiotensininduced SMCs reduced the proliferation of SMCs. It has been shown that Lnc-Ang362 is proximal to miR-221 and miR-222, which are known to play a role in VSMC proliferation, and that it reduces the expression of the two miRNAs (42).

Macrophages are among the cells that play a role in the formation and development of atherosclerosis. The accumulation of cholesterol by macrophages is one of the pathological characteristics of atherosclerosis. Monocyte/macrophage differentiation is controlled by a complex process and requires cooperative expression of the stage-specific transcription factors, various cytokines, and ncRNAs. Chen et al. (43) reported two ncRNAs: lncRNA monocyte (lnc-MC) and miR-199a-5p, which are regulated by PU.1 with opposite roles during monocyte/macrophage differentiation. Lnc-MC acts as a sponge for miR-199a-5p and promotes monocyte/macrophage differentiation, and it can reduce the suppression on the expression of activin receptor type 1B (ACVR1B), which is an important monocyte/macrophage differentiation regulator. In another study, lincRNA-Cox2 in rodent macrophages was reported to decrease $(\mathrm{Ccl} 5)$ as well as increase (interleukin [IL]-6) the expressions of cytokines that are associated with atherosclerosis via a nuclear factor kappa (NFKB)-dependent pathway (44).

Atherosclerosis is a complex disease that shows a polygenic and multifactorial inheritance pattern. In addition to IncRNAs acting on pro-atherogenic cells, several other lncRNAs play a role in this process. For example, $\mathrm{Hu}$ et al. (45) have identified lincRNA-DYNLRB2-2 induced at a significant level by oxidized low-density lipoprotein (oxLDL) in THP-1 macrophage-derived foam cells in apoE -/- mice and have shown that it reduces the severity of atherosclerosis (45). In another study, IncRNA apolipoprotein A1 -antisense (APOA1-AS) has been shown to function as a negative transcriptional regulator and to be the regulator of distinct histone methylation patterns of APOA1, which is the major component of high-density lipoprotein particles (46).

\section{Conclusion}

Studies have shown that IncRNAs have important roles in the etiology and prognosis of atherosclerosis. Identification of lncRNAs involved in the formation and development of atherosclerosis continues with RNA-based studies being performed. The process of elucidating the functions of lncRNAs is still on the onset. Further research is needed in this regard. The presence of various transcript variants of lncRNAs and the facts that these variants have different functions, a very rapid degradation, and very low intracellular expression levels render the studies difficult. However, the fact that lncRNAs participate in the atherosclerosis process is indicated by functional genomic studies and it is suggested that that they may be the targets for therapeutic uses in the future.

Author Contributions: Concept - B.B.; Design - B.B.; Supervision - M.C.; Resources - B.B.; Materials - B.B.; Data Collection and/or Processing - B.B.; Analysis and/or Interpretation - B.B., M.C.; Literature Search - B.B.; Writing Manuscript - B.B.; Critical Review - M.C.

Conflict of Interest: No conflict of interest was declared by the authors.

Financial Disclosure: The authors declared that this study has received no financial support.

\section{References}

1. Peters SA, den Ruijter HM, Bots ML, Moons KG. Improvements in risk stratification for the occurrence of cardiovascular disease by imaging subclinical atherosclerosis: a systematic review. Heart 2012; 98: 177-84. [CrossRef]

2. Uchida $S$, Dimmeler $S$. Long noncoding RNAs in cardiovascular diseases. Circ Res 2015; 116: 737-50. [CrossRef]

3. Kornfeld JW, Brüning JC. Regulation of metabolism by long, noncoding RNAs. 2014; 5: 57.

4. Wang K, Long B, Zhou LY, Liu F, Zhou QY, Liu CY, et al. CARL lncRNA inhibits anoxia-induced mitochondrial fission and apoptosis in cardiomyocytes by impairing miR-539-dependent PHB2 downregulation. Nat Commun 2014; 5: 3596. [CrossRef]

5. Yang Y, Li H, Hou S, Hu B, Liu J, Wang J. The noncoding RNA expression profile and the effect of lncRNA AK126698 on cisplatin resistance in non-small-cell lung cancer cell. PLoS One 2013; 8: e65309.

6. Cabili MN, Trapnell C, Goff L, Koziol M, Tazon-Vega B, Regev A, et al. Integrative annotation of human large intergenic noncoding RNAs reveals global properties and specific subclasses. 2011; 25: 1915-27.

7. Leung A, Stapleton K, Natarajan R. Functional Long Non-coding RNAs in Vascular Smooth Muscle Cells. 2016; 394: 127-41.

8. Bird AP. CpG-rich islands and the function of DNA methylation. Nature 1986; 321: 209-13. [CrossRef]

9. Rizki G, Boyer LA. Lncing epigenetic control of transcription to cardiovascular development and disease. Circ Res 2015; 117: 192-206. [CrossRef] 
10. Mercer TR, Mattick JS. Structure and function of long noncoding RNAs in epigenetic regulation. Nat Struct Mol Biol 2013; 20: 300-7. [CrossRef]

11. Zhao J, Sun BK, Erwin JA, Song JJ, Lee JT. Polycomb proteins targeted by a short repeat RNA to the mouse X chromosome. Science 2008; 322: 750-6. [CrossRef]

12. Froberg JE, Yang L, Lee JT. Guided by RNAs: X-inactivation as a model for lncRNA function. J Mol Biol 2013; 425: 3698-706. [CrossRef]

13. Mohammad F, Pandey GK, Mondal T, Enroth S, Redrup L, Gyllensten $\mathrm{U}$, et al. Long noncoding RNA-mediated maintenance of DNA methylation and transcriptional gene silencing. Development 2012; 139: 2792-803. [CrossRef]

14. Berghoff EG, Clark MF, Chen S, Cajigas I, Leib DE, Kohtz JD. Evf2 (Dlx6as) lncRNA regulates ultraconserved enhancer methylation and the differential transcriptional control of adjacent genes. Development 2013; 140: 4407-16. [CrossRef]

15. Martens JA, Laprade L, Winston F. Intergenic transcription is required to repress the Saccharomyces cerevisiae SER3 gene. Nature 2004; 429: 571-4. [CrossRef]

16. Wang X, Arai S, Song X, Reichart D, Du K, Pascual G, et al. Induced ncRNAs allosterically modify RNA-binding proteins in cis to inhibit transcription. Nature 2008; 454: 126-30. [CrossRef]

17. Lin R, Roychowdhury-Saha M, Black C, Watt AT, Marcusson EG, Freier SM, et al. Control of RNA processing by a large non-coding RNA over-expressed in carcinomas. FEBS Lett 2011; 585: 671-6. [CrossRef]

18. Souquere S, Beauclair G, Harper F, Fox A, Pierron G. Highly ordered spatial organization of the structural long noncoding NEAT1 RNAs within paraspeckle nuclear bodies. Mol Biol Cell 2010; 21: 4020-7. [CrossRef]

19. Cesana M, Cacchiarelli D, Legnini I, Santini T, Sthandier O, Chinappi $\mathrm{M}$, et al. A long noncoding RNA controls muscle differentiation by functioning as a competing endogenous RNA. Cell 2011; 147: 358-69. [CrossRef]

20. Onat D, Brillon D, Colombo PC, Schmidt AM. Human vascular endothelial cells: a model system for studying vascular inflammation in diabetes and atherosclerosis. Curr Diab Rep 2011; 11: 193-202. [CrossRef]

21. Helgadottir A, Thorleifsson G, Manolescu A, Gretarsdottir S, Blondal T, Jonasdottir A, et al. A common variant on chromosome 9p21 affects the risk of myocardial infarction. Science 2007; 316: 1491-3. [CrossRef]

22. Çakmak HA, Bayoğlu B, Durmaz E, Can G, Karadağ B, Cengiz M, et al. Evaluation of association between common genetic variants on chromosome 9p21 and coronary artery disease in Turkish population. Anatol J Cardiol 2015; 15: 196-203. [CrossRef]

23. Holdt LM, Hoffmann S, Sass K, Langenberger D, Scholz M, Krohn K et al. Alu elements in ANRIL non-coding RNA at chromosome 9p21 modulate atherogenic cell functions through trans-regulation of gene networks. PLoS Genet 2013; 9: e1003588.

24. Holdt LM, Teupser D. Recent studies of the human chromosome 9p21 locus, which is associated with atherosclerosis in human populations. Arterioscler Thromb Vasc Biol 2012; 32: 196-206. [CrossRef]

25. Yap KL, Li S, Muñoz-Cabello AM, Raguz S, Zeng L, Mujtaba S, et al. Molecular interplay of the noncoding RNA ANRIL and methylated histone $\mathrm{H} 3$ lysine 27 by polycomb CBX7 in transcriptional silencing of INK4a. Mol Cell 2010; 38: 662-74. [CrossRef]

26. Kotake Y, Nakagawa T, Kitagawa K, Suzuki S, Liu N, Kitagawa M, et al. Long non-coding RNA ANRIL is required for the PRC2 recruitment to and silencing of p15(INK4B) tumor suppressor gene. Oncogene 2011; 30: 1956-62. [CrossRef]
27. Bayoglu B, Cakmak HA, Yuksel H, Can G, Karadag B, Ulutin T, et al. Chromosome 9p21 rs10757278 polymorphism is associated with the risk of metabolic syndrome. Mol Cell Biochem 2013; 379: 77-85. [CrossRef]

28. Bayoglu B, Yuksel H, Cakmak HA, Dirican A, Cengiz M. Polymorphisms in the long non-coding RNA CDKN2B-AS1 may contribute to higher systolic blood pressure levels in hypertensive patients. Clin Biochem 2016; 49: 821-7. [CrossRef]

29. Bayoglu B, Arslan C, Gode S, Kaya Dagistanli F, Arapi B, Burc Deser $\mathrm{S}$, et al. The severity of internal carotid artery stenosis is associated with the cyclin-dependent kinase inhibitor $2 \mathrm{~A}$ gene expression. J Atheroscler Thromb 2014; 21: 659-71. [CrossRef]

30. Jarinova O, Stewart AF, Roberts R, Wells G, Lau P, Naing T, et al. Functional analysis of the chromosome $9 \mathrm{p} 21.3$ coronary artery disease risk locus. Arterioscler Thromb Vasc Biol 2009; 29: 1671-7. [ CrossRef]

31. Holdt LM, Beutner F, Scholz M, Gielen S, Gäbel G, Bergert H, et al. ANRIL expression is associated with atherosclerosis risk at chromosome 9p21. Arterioscler Thromb Vasc Biol 2010; 30: 620-7. [CrossRef]

32. Yan B, Yao J, Liu JY, Li XM, Wang XQ, Li YJ, et al. IncRNAMIAT regulates microvascular dysfunction by functioning as a competing endogenous RNA. Circ Res 2015; 116: 1143-56. [CrossRef]

33. Zachary I. VEGF signalling: integration and multi-tasking in endothelial cell biology. Biochem Soc Trans 2003; 31: 1171-7. [CrossRef]

34. Ji P, Diederichs S, Wang W, Böing S, Metzger R, Schneider PM, et al. MALAT-1, a novel noncoding RNA, and thymosin beta4 predict metastasis and survival in early-stage non-small cell lung cancer. Oncogene 2003; 22: 8031-41. [CrossRef]

35. Michalik KM, You X, Manavski Y, Doddaballapur A, Zörnig M, Braun $\mathrm{T}$, et al. Long noncoding RNA MALAT1 regulates endothelial cell function and vessel growth. Circ Res 2014; 114: 1389-97. [CrossRef]

36. Watts R, Johnsen VL, Shearer J, Hittel DS. Myostatin-induced inhibition of the long noncoding RNA Malat1 is associated with decreased myogenesis. Am J Physiol Cell Physiol. 2013; 304: C995-1001.

37. van Vlijmen BJ, Gerritsen G, Franken AL, Boesten LS, Kockx MM, Gijbels MJ, et al. Macrophage p53 deficiency leads to enhanced at-

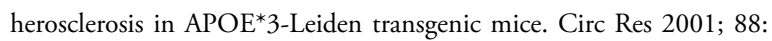
780-6. [CrossRef]

38. Mercer J, Bennett M. The role of $\mathrm{p} 53$ in atherosclerosis. Cell Cycle 2006; 5: 1907-9. [CrossRef]

39. Huarte M, Guttman M, Feldser D, Garber M, Koziol MJ, KenzelmannBroz D, et al. A large intergenic noncoding RNA induced by $\mathrm{p} 53$ mediates global gene repression in the p53 response. Cell 2010; 142: 409-19. [CrossRef]

40. Wu G, Cai J, Han Y, Chen J, Huang ZP, Chen C, et al. LincRNA-p21 regulates neointima formation, vascular smooth muscle cell proliferation, apoptosis, and atherosclerosis by enhancing p 53 activity. Circulation 2014; 130: 1452-65. [CrossRef]

41. Brasier AR, Recinos A 3rd, Eledrisi MS. Vascular inflammation and the renin-angiotensin system. Arterioscler Thromb Vasc Biol 2002; 22: 1257-66. [CrossRef]

42. Leung A, Trac C, Jin W, Lanting L, Akbany A, Saetrom P, et al. Novel long noncoding RNAs are regulated by angiotensin II in vascular smooth muscle cells. Circ Res 2013; 113: 266-78. [CrossRef]

43. Chen MT, Lin HS, Shen C, Ma YN, Wang F, Zhao HL, et al. PU.1Regulated Long Noncoding RNA lnc-MC Controls Human Monocyte/Macrophage Differentiation through Interaction with MicroRNA 199a-5p. Mol Cell Biol 2015; 35: 3212-24. [CrossRef] 
44. Carpenter S, Aiello D, Atianand MK, Ricci EP, Gandhi P, Hall LL, et al. A long noncoding RNA mediates both activation and repression of immune response genes. Science 2013; 341: 789-92. [CrossRef]

45. Hu YW, Yang JY, Ma X, Chen ZP, Hu YR, Zhao JY, et al. A lincRNADYNLRB2-2/GPR119/GLP-1R/ABCA1-dependent signal transducti- on pathway is essential for the regulation of cholesterol homeostasis. J Lipid Res 2014; 55: 681-97. [CrossRef]

46. Lund-Katz S, Phillips MC. High density lipoprotein structure-function and role in reverse cholesterol transport. Subcell Biochem 2010; 51 : 183-227. [CrossRef] 